\title{
Comparison of Anthropometric Dimensions in Healthy and Disabled Individuals
}

\author{
Amir Hossein Davoudian Talab, ${ }^{1,}$ Ahmad Badee Nezhad, ${ }^{2}$ Nasrin Asadi Darvish,, ${ }^{2}$ and Hossein \\ Molaeifar ${ }^{3}$ \\ ${ }^{1}$ Department of Occupational Hygiene, Behbahan School of Medical Science, Behbahan, IR Iran \\ ${ }^{2}$ Department of Environmental Health, Behbahan School of Medical Science, Behbahan, IR Iran \\ ${ }^{3}$ Student Research Committee, Behbahan School of Medical Sciences, Behbahan, IR Iran \\ "Corresponding author: Amir Hossein Davoudian Talab, Department of Occupational Hygiene, Behbahan School of Medical Science, Behbahan, IR Iran. E-mail: \\ amirhosaindavudian@yahoo.com
}

Received 2016 March 10; Revised 2016 May 07; Accepted 2016 May 10.

\begin{abstract}
Background: Anthropometry is a very accurate tool in ergonomic design process; the design of appropriate rehabilitation equipment based on anthropometric data results in disabled empowerment, decreased health expenses, and allows disabled individuals to live and act in the society like other healthy citizens. The purpose of this study was to determine anthropometric dimensions of disabled male and female cases (wheelchair users) and compare this with healthy individuals.

Methods: This analytic-descriptive study was performed during year 2012 in Tehran city. The sample population consisted of 314 disabled and healthy individuals, including 150 healthy and 79 disabled males and 50 healthy and 35 disabled females. The age range of samples was 25 to 55 years old. Disabled individuals were manual wheelchair paraplegic users while healthy participants were official staff. The simple probability sampling method was used. In this research, 9 (9) anthropometric dimensions, applied for designing wheelchair and seats, were measured.

Results: This research showed that the average sitting height was $78.4 \pm 6.75 \mathrm{~cm}$ among disabled males and $58.47 \pm 4.5 \mathrm{~cm}$ among disabled females. Also, the sitting height was 90.97 \pm 3.55 among healthy males and $83.72 \pm 4.54$ among healthy females. Comparison between healthy and disabled male and female subjects showed that 6 out of 9 dimensions had a significant difference between them $\mathrm{P}<0.05$; also, comparison of two studies from America and Poland, showed that the hip dimension of Iranian wheel chair users was greater.

Conclusions: The results indicate significant differences among healthy and disabled individuals in anthropometric dimensions and the highest difference was found in the height dimension and access limits.
\end{abstract}

Keywords: Ergonomics, Anthropometry, Disabled People

\section{Background}

Ergonomics is the science that deals with recognizing the interaction between humans and other system components. This science makes use of theories, principles, and methods in design, in order to allow healthy and appropriate performance of the system. Anthropometry is a component of ergonomics (1).

A very useful tool in the design process is the application of anthropometry, which is the science of particular body measurements in order to differentiate between individuals, groups, etc. Anthropometry is the measurement of the dimensions and certain other physical characteristics of the body, such as volumes, centers of gravity, inertial properties, mass, and body segments (2).

Experts of ergonomics use anthropometric data to determine the figure and size of the living place, workplace, and tools used by people in all fields of rehabilitation, mil- itary, industrial, educational, and sport (3). People with physical disabilities either due to chronic sickness or aging or some other reasons have to spend a large part of their time in a seated posture or confined to wheelchairs (4). At least $2.6 \%$ (6.8million) of the US population use assistive devices and nearly a quarter of those using assistive devices utilize a manual wheelchair for mobility (5).

This tool assists with self-reliance and active participation in social settings and is used by most physically disabled people. It is clear that the proper design of such a tool is the main effective factor in its application by disabled individuals (6). In other words, the design of appropriate equipment based on anthropometric data results in disabled empowerment, decreased health expenses and allows disabled individuals to live and act in the society like other healthy people (7). The general lack of anthropometric information about individuals, who are using wheelchairs, limits the ability of designers to create envi- 
ronments and products that could be used effectively and safely by this diverse set of users (2) 2012b. Therefore, studies showed that the anthropometric data used by experts and designers, dates back to more than 3 decades. It is clear that during this period, people, population demography, and physical features have undergone severe changes (8). Hence, such data, although available for healthy individuals, is rare for disabled people, who use wheelchairs (9). Also, some designers have designed equipment for disabled people based on the features of healthy people (10). However, due to the low capability of disabled individuals, it is not rational to design their equipment based on the characteristics of healthy people (11). Studies that have been conducted in the field of anthropometry wheelchair users, include Paquet and Feathers studies (2004) on 120 male wheelchair users, which determined static anthropometric dimensions (12), and the study of Lucero-Duarte et al. (2012a), in which the aim of the study was to obtain anthropometric data of adult wheelchair users in Mexico. This study included 108 disabled people (56 males and 52 females) using wheelchair and having sufficiently efficient upper extremities to perform professional activities (1). In the study of Wang et al. (2014), a set of wheelchair users' oriented functional clothing was designed (5). However, although important, in Iran, there are practically no studies of this nature and there are only studies applied to people without any disability.

Therefore, due to the importance of determining anthropometric dimensions in the design of equipment and safe living environment for disabled and healthy people and lack of anthropometric data related to wheelchair users in Iran, the purpose of this study was to determine anthropometric dimensions of disabled males and females (wheelchair users), and to compare this with common healthy individuals. This study attempted to answer the question of whether support devices could be designed for disabled cases based on the anthropometric data of healthy individuals.

\section{Methods}

This analytic-descriptive study was performed during year 2012 in Tehran City. The sample population consisted of 314 disabled and healthy individuals, including 150 healthy and 79 disabled males and 50 healthy and 35 disabled females. It is important to note that anthropometric data is influenced by factors, such as age and occupation, type of disability, and degree of disability (1). In order to avoid the aging process, in this study, the age range of the samples was 25 to 55 years old. Disabled individuals were manual wheelchair paraplegic users with their upper extremities sufficiently efficient to perform professional activities, while healthy participants were official staff. The simple probability sampling method was used. In this research, 9 anthropometric dimensions that are applied in designing wheelchairs and seats were measured. Figure 1 shows static measurements, including height, length, and width. After obtaining contact with official staff and wheelchair users, individuals were held in standard posture and dimensions were measured based on the studies of Flayed, Patio, Kozy, and Harrows (9, 11-13). Measurements were performed while males had underwear and females had loose clothing and were without shoes; after body physical measurements some modifications were applied on their shoes $(2.5 \mathrm{~cm}$ added heel). The standard posture of disabled users on wheelchair and official staff on ergonomic seats is such that individuals sit on a horizontal plane and enhance their body as much as possible, look straight forward, free their shoulders, hang their elbows vertically, and their thighs and wrists are in the horizontal position while the calf is in a vertical position. In order to maintain this position in disabled people, an adjustable chair was used in order to support the thighs and calf. This research included measurements of disabled individuals without wheelchairs, also referred to as sitting position measurements $(12,14)$. In this study, tools such as 1 : Standard anthropometric chair, 2: Caliper in large and small sizes, 3: Tape meter and metal meter ( $1 \mathrm{~mm}$, accuracy), 4 : Steadio meter (1 mm, accuracy) and scaled board of anthropometry were used for body measurements. The measurements were done by occupational health experts, who had passed essential training for anthropometry. Figure 1 demonstrates measured dimensions in standard physical statements of anthropometry in sitting postures.

Measurements were performed by experts trained in this field. The following formula was used to determine the sample size of disabled and healthy individuals; sample size of the study was determined based on pre-test analysis on a group of 20 wheelchair users and office workers. Also, t test was used for comparison of anthropometric dimensions between males and females and also between healthy and disabled people. For statistical analysis, the SPSS 16 software was used.

Precision was obtained in three continuous measurements as $0.92 \%$ and $0.88 \%$ for disabled and healthy individuals, respectively.

$$
\begin{aligned}
n & =\frac{z^{2} s^{2}}{d^{2}} \\
n & =\left(1.645 \times \frac{6}{092}\right)^{2} \\
& =141 \text { (To disabled people) }
\end{aligned}
$$




\begin{tabular}{|c|c|c|}
\hline A & Sitting Height & Floor to Top of the Head \\
\hline B & Eye Height & Floor to Centre of the Eye \\
\hline C & $\begin{array}{c}\text { Shoulder } \\
\text { Height }\end{array}$ & Floor to Acromion \\
\hline D & $\begin{array}{c}\text { Popliteal Length } \\
\text { E }\end{array}$ Popliteal Height & Popliteal Cavity - Floor \\
\hline F & $\begin{array}{c}\text { Hip-knee } \\
\text { Length }\end{array}$ & $\begin{array}{c}\text { Posterior Side of the } \\
\text { Buttocks - Articular Line of } \\
\text { the Popilteat Cavity }\end{array}$ \\
\hline G & $\begin{array}{c}\text { Hip Breadth } \\
\text { H }\end{array}$ & $\begin{array}{c}\text { Lateral Aspect of the Hip } \\
\text { Breadth }\end{array}$ \\
\hline I & $\begin{array}{c}\text { Arm Reach } \\
\text { Forward }\end{array}$ & $\begin{array}{c}\text { Lateral Aspect of the } \\
\text { Deltoids at the Shoulder } \\
\text { Level }\end{array}$ \\
\hline
\end{tabular}
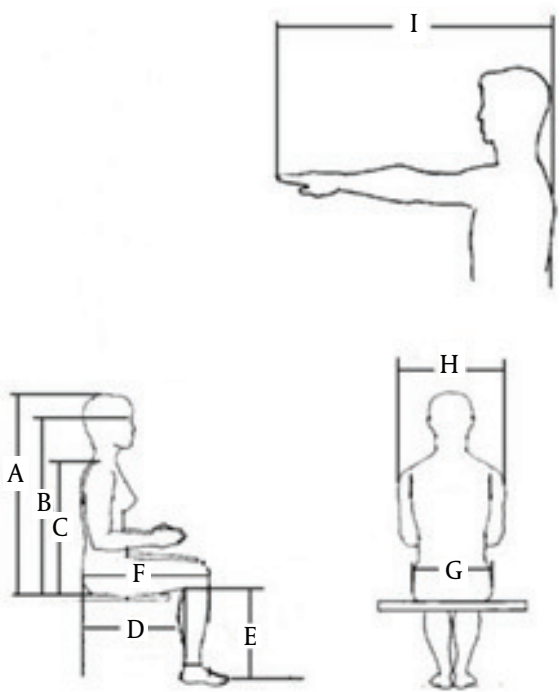

Figure 1. Dimensions of Anthropometry Based on the Method of Standard Measurements ISO/IDS7250; Sitting Postures

$$
\begin{aligned}
n & =(1.645 \times 7.2 / 0.88)^{2} \\
& =181(\text { To healthy people })
\end{aligned}
$$

\section{Results}

In this study, an average of 9 (9) healthy and disabled body dimensions were obtained from 25- to 55-year-olds in sitting position on wheelchair and ergonomic chairs (Table 1). This research showed that the average sitting height was $78.4 \pm 6.75 \mathrm{~cm}$ among disabled males and $58.47 \pm 4.5$ $\mathrm{cm}$ among disabled females. Also, the sitting height was 90.97 \pm 3.55 among healthy males and $83.72 \pm 4.54$ among healthy females. This result showed higher average rate of sitting height among healthy participants compared to cases with disability. Also, in this study, 9 (9) body dimensions of healthy and disabled people were compared. Comparison between healthy and disabled male and female subjects showed that 6 dimensions out of 9 had a significant difference between them, $\mathrm{P}<0.05$ (Tables 2 and 3). The results of this study, in comparison with two studies in America and Poland, showed that the hip dimension of Iranian wheel chair users was greater (Table 4). However, the male and female sitting and popliteal height in the two countries was greater compared to Iranian wheel chair users.

\section{Discussion}

A comparison test related to disabled and healthy people's body dimensions showed that sitting height, eye height, shoulder height, and Arm reach forward and also hip breadth in healthy males was significantly greater than disabled cases. There was no significant difference between disabled and healthy people in shoulder breadth, popliteal length, and front knee-hip length (Table 2). Comparison of healthy controls and disabled females showed that the heights reached by healthy females was greater than disabled females, yet there was no significant difference in shoulder breadth, hip breadth, and popliteal length (Table 3). A study by Jarosz et al. among wheelchair users with upper body common physical activity showed that healthy people had greater work place and work space than disabled cases (13). The measurements used to design back rest and height of desk should emphasize on the differences between healthy and disabled males and females to design suitable workstations $(1,8)$.

Also, forward reach in healthy people was greater than disabled cases, similar to the current study. In the study of Nowak et al., forward reach was about $30 \mathrm{~cm}$ more than disabled people and reach forward in healthy males in Bolestad and Monica studies was 84.7 and $83.3 \mathrm{~cm}$, respectively (14-16). This dimension is applied to determine maximum barriers distance, controls and tools surrounding 
Table 1. Average Anthropometry Dimension Among Healthy and Disabled Males and Females (CM)

\begin{tabular}{|c|c|c|c|c|c|c|c|c|c|}
\hline \multirow[t]{2}{*}{ Variables } & \multirow{2}{*}{$\begin{array}{c}\text { Group } \\
\text { Dimension }\end{array}$} & \multicolumn{2}{|c|}{ Healthy Males (Official Staff) N=15 } & \multicolumn{2}{|c|}{ Healthy Females (Official Staff), $\mathrm{N}=\mathbf{5 0}$} & \multicolumn{2}{|c|}{ Disabled Males (Wheelchair User), $\mathrm{N}=79$} & \multicolumn{2}{|c|}{ Disabled Females (Wheelchair User), $\mathrm{N}=35$} \\
\hline & & mean & SD & mean & SD & mean & SD & mean & SD \\
\hline 1 & Sitting height & 90.79 & 3.55 & 83.72 & 4.54 & 78.4 & 6.75 & 57 & 5.5 \\
\hline 3 & Shoulder height & 80.25 & 3.57 & 56.78 & 4 & 52.6 & 6.34 & 96.4 & 5.76 \\
\hline 4 & Arm reach forward & 38.86 & 2.32 & 50.81 & 5.37 & 85.15 & 5.58 & 55.39 & 5.46 \\
\hline 5 & Shoulder breadth & 59.12 & 3.06 & 56 & 7.74 & 44.6 & 4 & 42.07 & 4.5 \\
\hline 6 & Hip breadth & 47.79 & 2.89 & 46.86 & 4.35 & 36.39 & 3.95 & 39.5 & 6.3 \\
\hline 7 & Popliteal heights & 38.50 & 2.81 & 37.71 & 4.27 & 43.64 & 3.96 & 38.3 & 3.8 \\
\hline 8 & Popliteal length & 45.66 & 5.10 & 40.1 & 3 & 48.14 & 4.02 & 46 & 4.4 \\
\hline 9 & Knee-hip length & 69.64 & 3.53 & 58 & 3.46 & 58.47 & 4.5 & 58.47 & 4.5 \\
\hline
\end{tabular}

Table 2. Comparison of Anthropometry Dimensions Among Healthy and Disabled Males in Sitting Position with t Test

\begin{tabular}{|c|c|c|c|c|}
\hline No. & Body Dimensions & Healthy Male, $N=150$ & Disabled Male, $N=79$ & P Value \\
\hline 1 & Sitting height & 90.79 & 78.4 & 0.001 \\
\hline 2 & Shoulder height & 62.09 & 52.6 & 0.001 \\
\hline 3 & Eye height sitting & 80.25 & 67 & 0.001 \\
\hline 4 & Popliteal height & 38.86 & 43.46 & 0.001 \\
\hline 5 & Front-knee length & 59.12 & 85.47 & 0.1 \\
\hline 6 & Popliteal-hip length & 48.14 & 47.79 & 0.6 \\
\hline 7 & Hip breadth & 38.50 & 36.39 & 0.001 \\
\hline 8 & Shoulder breadth & 45.66 & 44.6 & 0.1 \\
\hline 9 & Arm reach forward & 69.64 & 58.15 & 0.001 \\
\hline
\end{tabular}

Table 3. Comparison of Anthropometry Dimensions Among Healthy and Disabled Females in Sitting Position with $\mathrm{t}$ Test

\begin{tabular}{|c|c|c|c|c|}
\hline No. & Dimensions & Healthy Females, $N=50$ & Disabled Females, $\mathbf{N}=35$ & P Value \\
\hline $\mathbf{1}$ & Sitting height & 83.72 & 71.74 & 0.001 \\
\hline 2 & Shoulder height & 73.93 & 60.7 & 0.001 \\
\hline 3 & Eye height sitting & 56.87 & 47.2 & 0.001 \\
\hline 4 & Popliteal height & 50.81 & 38.3 & 0.001 \\
\hline 5 & Front-knee length- & 56 & 57.47 & 0.52 \\
\hline 6 & Popliteal-hip length & 46.86 & 46 & 0.61 \\
\hline 7 & Hip breadth & 40.1 & 39.5 & 0.11 \\
\hline 8 & Shoulder breadth & 37.71 & 42.7 & 0.001 \\
\hline 9 & Arm reach forward & 58 & 55.39 & 0.001 \\
\hline
\end{tabular}

the work table, and factors essential for improvement of interactions between users with workstation (7).

Due to the usage of sitting height and eye height applied to design work station units and control panels and sit back height in work places, and determination of reaches in adjusting barriers distance, controls and equipment's near the worktable $(1,3,7,8,17)$, differences in the body dimension of healthy and disabled people results in differences in work place size. Failure to consider these differences when designing a work place causes incompatibility with individual features and results in dissatisfaction, stress, and musculoskeletal disorders in disabled cases $(18,19)$, due to the fact that they have more physical requirements, compared to healthy people (8). 


\begin{tabular}{|c|c|c|c|c|c|c|c|c|c|c|c|c|}
\hline \multirow{4}{*}{$\begin{array}{l}\text { Body Dimension } \\
\text { Percentile }\end{array}$} & \multicolumn{4}{|c|}{ Iranian Wheelchair User } & \multicolumn{4}{|c|}{ Poland Wheelchair User } & \multicolumn{4}{|c|}{ American Wheelchair User } \\
\hline & \multicolumn{2}{|c|}{ Male } & \multicolumn{2}{|c|}{ Female } & \multicolumn{2}{|c|}{ Male } & \multicolumn{2}{|c|}{ Female } & \multicolumn{2}{|c|}{ Male } & \multicolumn{2}{|c|}{ Female } \\
\hline & \multicolumn{2}{|c|}{79} & \multicolumn{2}{|c|}{35} & \multicolumn{2}{|c|}{101} & \multicolumn{2}{|c|}{69} & \multicolumn{2}{|c|}{37} & \multicolumn{2}{|c|}{28} \\
\hline & mean & SD & 5 & 95 & mean & DS & 5 & 95 & mean & SD & 5 & 95 \\
\hline \multicolumn{13}{|l|}{ Hip breadth } \\
\hline Male & 36.39 & 3.95 & 31.15 & 44.7 & 32.94 & 8.5 & 19 & 46.9 & 26.3 & 3.9 & 22.4 & 38.7 \\
\hline Female & 39.5 & 6.3 & 31 & 52.1 & 32.89 & 3.86 & 26.6 & 39.2 & 27.7 & 5.2 & 21.6 & 38.3 \\
\hline \multicolumn{13}{|l|}{ Shoulder breadth } \\
\hline Male & 44.6 & 4 & 39 & 52 & 39.26 & 2.38 & 35.3 & 42.5 & 53.4 & 5.2 & 46.7 & 63.3 \\
\hline Female & 42.07 & 4.5 & 35.8 & 52.1 & 35.29 & 2.57 & 31 & 39.4 & 51.2 & 6.5 & 39.1 & 62 \\
\hline \multicolumn{13}{|l|}{ Popliteal length } \\
\hline Male & 48.14 & 4.02 & 40 & 54.1 & 54.88 & 5.24 & 46.1 & 63.6 & 52.2 & 6.8 & 39.2 & 60.9 \\
\hline \multicolumn{13}{|l|}{ Sitting height } \\
\hline Male & 78.4 & 6.75 & 66 & 87.7 & 86.44 & 5.85 & 76.9 & 96 & 79.6 & 6 & 67.8 & 85 \\
\hline Female & 71.74 & 5.63 & 61.2 & 80.2 & 78.10 & 6.91 & 66.8 & 89.4 & 75.3 & 4.9 & 66.3 & 83.3 \\
\hline
\end{tabular}

Results of this study showed that the body dimensions of disabled people differ from healthy people. Studies showed that disorder in joints performance, ligament, and neural- muscle system in disabled people results in deformation of parts of the body and finally results in complete deformation of body dimensions. As a result leads to a change in body size dimension (17-20). The other restricting factor of body growth is restriction of mobility activity, pain-induced stresses, lack of rehabilitation facilities, and residence in clinical and rehabilitation centers for disabled individuals (21). Other studies showed that a shorter sitting height and lower access limits disabled people, compared to healthy people, which is because of deformation of skeletal systems, looseness of back muscles, and difficulty in keeping the body in a straight position (22).

Similar to what happens in the aging process, the deficit tonicity of postural muscles increases back hypnosis and simultaneously decreases cartilage thickness between 2 vertebrates, which finally results in shortened sitting and back height (17). Other studies showed that declining hip and tight muscles decreased body height among disabled people (23). In this study, the mean of 4 body dimensions of Iranian wheelchair users was compared with 2 studies conducted in America and Poland (Table 4). The result of this study showed that the width of shoulders and the width of buttocks in the Iranian population are higher than the 2 other Poland and American wheelchair user populations. These dimensions are very important in designing back rests and width of wheelchair $(2,6)$, yet sitting height and sitting popliteal height in Iranian wheelchair user populations are less than the 2 other populations; sitting position dimensions are important for designing office workstations, desks, chairs and wheelchairs. These di- mensions are used in designing different dimensions of chairs, such as chair height and length of seat (24).

\subsection{Conclusion}

This paper summarized the structural anthropometric dimensions of 114 male and female wheelchair users in comparison with 200 male and female office workers. Due to the limitations of the study regarding the lack of access to advanced tools for anthropometric dimension measurements, such as digital and three-dimensional anthropometry measurement tools, there is a need for continued efforts that will improve our understanding of the anthropometry of wheelchair users. It appears that new measurement and data presentation methods will soon offer promising new ways of applying anthropometry in design for this important segment of the population. Also, this paper presents nine anthropometric measures for people using wheelchairs, which are essential for the design of workstations for any industry. Based on the results of the comparisons with other studies on populations of Poland and America, it could be concluded that body dimension of Iranian wheelchair users is different from the 2 mentioned countries; the results also indicate significant differences among healthy and disabled people in anthropometric dimensions and the highest difference was found in the height dimension and access limits.

\section{Acknowledgments}

The authors would like to sincerely thank the staff and management of the Behbahan Faculty of Medical Sciences for their cooperation and financial assistance in the course of this study and the vital information they provided. The authors declare that there was no conflict of interest. 


\section{Footnotes}

Authors' Contribution: Concepts, design, manuscript editing, manuscript review: Amirhossein Davudian talab; data analysis: Ahmad Badee nezhad; statistical analysis, manuscript preparation: Gholamreza Badfar; Literature search: Nasrin Asadi Darvish and Hossein Molaeifar

Funding/Support: This study was part of a Research projects by Amirhossein Davudian talab and special thanks goes to Behbahan faculty of Medical Sciences for the financial support via contract number CA9203.

\section{References}

1. Mououdi MA. Anthropometric Engineering. Mazandaran Univ Med Sci. 1996

2. Barros HO, Soares MM. Anthropometric analysis of wheelchair users: methodological factors which influence interpopulational comparison. Work. 2012;41 Suppl 1:4091-7. doi: 10.3233/WOR-2012-0702-4091. [PubMed: 22317348].

3. Mortazavi SB, Kanani Joze M, Khavanin A, Mirzaei R, Rasoolzadeh Y, Mansourizadeh $\mathrm{M}$, et al. Foot anthropometry by digital photography and the importance of its application in boot design [In Persian]. Journal Mil Med. 2008;10(1):69-80.

4. Moon Y, Jayaraman C, Hsu IM, Rice IM, Hsiao-Wecksler ET, Sosnoff JJ. Variability of peak shoulder force during wheelchair propulsion in manual wheelchair users with and without shoulder pain. Clin Biomech (Bristol, Avon). 2013;28(9-10):967-72. doi: 10.1016/j.clinbiomech.2013.10.004. [PubMed: 24210512].

5. Wang Y, Wu D, Zhao M, Li J. Evaluation on an ergonomic design of functional clothing for wheelchair users. Appl Ergon. 2014;45(3):5505. doi: 10.1016/j.apergo.2013.07.010. [PubMed: 23948502].

6. Steinfeld E, Maisel J, Feathers D, D'Souza C. Anthropometry and standards for wheeled mobility: an international comparison. Assist Technol. 2010;22(1):51-67. doi: 10.1080/10400430903520280. [PubMed: 20402047].

7. Mououdi MA, Choobine A. Ergonomics in Practice: Selected Essays on Ergonomics. Tehran: Center for the Book Publishing Media; 2009

8. Pheasant S. Bodyspace : anthropometry, ergonomics, and design. London: Taylor \& Francis; 1986. p. 275

9. Kozey JW, Das B. Determination of the normal and maximum reach measures of adult wheelchair users. Int JInd Ergon. 2004;33(3):205-13. doi:10.1016/j.ergon.2003.05.001.
10. Rice VJB. Ergonomics in health care and rehabilitation. Boston: Butterworth-Heinemann;1998. p. 369.

11. Kumar S. Perspectives in rehabilitation ergonomics. London, Bristol: Taylor \& Francis; 1997. p. 383.

12. Paquet V, Feathers D. An anthropometric study of manual and powered wheelchair users. Int J Ind Ergon. 2004;33(3):177-80. doi: 10.1016/j.ergon.2003.10.003.

13. Jarosz E. Determination of the workspace of wheelchair users. Int JInd Ergon. 1996;17(2):123-33. doi:10.1016/0169-8141(95)00044-5.

14. Nowak E. The role of anthropometry in design of work and life environments of the disabled population. Int J Ind Ergon. 1996;17(2):113-21. doi: 10.1016/0169-8141(95)00043-7.

15. Bolstad G, Benum B, Rokne A. Anthropometry of norwegian light industry and office workers. Appl Ergon. 2001;32(3):239-46. doi: 10.1016/S0003-6870(00)00067-3. [PubMed: 11394464].

16. Barroso MP, Arezes PM, da Costa LG, Sérgio Miguel A. Anthropometric study of Portuguese workers. Int J Ind Ergon. 2005;35(5):401-10. doi: 10.1016/j.ergon.2004.10.005.

17. Boussena M, Davies BT. Engineering anthropometry of employment rehabilitation centre clients. Appl Ergon. 1987;18(3):223-8. doi 10.1016/0003-6870(87)90008-1. [PubMed: 15676626].

18. Lane JP, Bauer SM. Assistive technology, technology transfer and ergonomics. Proc Hum Factors Ergon Soc Annu Meet. 2016;43(15):864-7. doi: 10.1177/154193129904301506.

19. Rader J, Jones D, Miller L. The importance of individualized wheelchair seating for frail older adults. J Gerontol Nurs 2000;26(11):24-32. doi: 10.3928/0098-9134-20001101-07. [PubMed: 11883618] quiz 46-7.

20. Goswami A, Ganguli S, Chatterjee BB. Anthropometric characteristics of disabled and normal Indian men. Ergonomics. 1987;30(5):817-23. doi: 10.1080/00140138708969770. [PubMed: 2956089].

21. Davudian Talab A, Tabatabai Ghumshe F, Osque Zade R, Azari G. Anthropometric Study of Paraplegic Wheelchair Users in Tehran [In Persian]. Iran J War Public Health. 2013;5(3):22-31.

22. Floyd WF, Guttmann L, Noble CW, Parkes KR, Ward J. A study of the space requirements of wheelchair users. Paraplegia. 1966;4(1):24-37. doi: 10.1038/sc.1966.2. [PubMed: 5962155].

23. Curtis KA, Drysdale GA, Lanza RD, Kolber M, Vitolo RS, West R. Shoulder pain in wheelchair users with tetraplegia and paraplegia. Arch Phys Med Rehabil. 1999;80(4):453-7. doi: 10.1016/S0003-9993(99)90285-X. [PubMed: 10206610].

24. Davoudian Talab A, Meshkani M, Nourian S, Mofidi A. Anthropometric dimensions of Iranian male workers and comparison with three Asian Countries. Int J Occup Environ Hyg. 2015;5(4):166-71. 